\title{
POTENCIALIDADES DO USO DE APLICATIVOS MÓVEIS NO COMPARTILHAMENTO DE ESTRATÉGIAS CONTEMPLANDO À ATUAÇÃO PROFISSIONAL DOCENTE
}

\author{
Sergio Reni Tiecher, UFSM, tiecher@gmail.com \\ Ana Cláudia Oliveira Pavão, UFSM, anaclaudiaoliveirapavao@gmail.com
}

\begin{abstract}
Resumo: A aprendizagem móvel está cada vez mais inserida no contexto educacional e tem apontado para a necessidade de utilização de novos recursos e metodologias na prática dos profissionais docentes, no que tange ao desenvolvimento e compartilhamento de conteúdo utilizados em sala de aula. Entre as possibilidades oferecidas atualmente estão os aplicativos que permitem o compartilhamento dessas estratégias de ensino. Este estudo tem como objetivo analisar como um aplicativo de compartilhamento de conteúdo pode contribuir com a prática docente. Trata-se de uma pesquisa aplicada, de abordagem qualitativa. Os sujeitos são professores do ensino técnico e o instrumento utilizado para coleta de dados foi o questionário. Foi utilizada a análise categorial para a análise dos dados, tendo sido elencadas três categorias, usabilidade, aspectos técnicos e prática pedagógica. Os resultados demonstram que ao utilizar a ferramenta como estímulo na produção de unidades de estudo, os professores compartilharam o seu próprio trabalho, promovendo a troca de conteúdos e enaltecendo as características da ferramenta, em relação aos demais meios convencionais até então utilizados na produção de conteúdo. Portanto, conclui-se que a utilização de um aplicativo contribui com melhores práticas e estratégias de compartilhamento de conteúdo entre os docentes.
\end{abstract}

Palavras-chave: Aplicativos. Aprendizagem móvel. Estratégias pedagógicas. Tecnologias educacionais em rede.

\section{POTENTIALS OF USING MOBILE APPLICATIONS IN SHARING STRATEGIES IN CONTEMPLATING TEACHING PROFESSIONALS}

\begin{abstract}
Mobile learning is increasingly inserted in the educational context and has pointed to the need to use new resources and methodologies in the practice of teaching professionals, with regard to the development and sharing of content used in the classroom. Among the possibilities currently offered are applications that allow the sharing of these teaching strategies. This study aims to analyze how a content sharing application can contribute to teaching practice. It is an applied research, with a qualitative approach. The subjects are teachers of technical education and the instrument used for data collection was the questionnaire. Categorical analysis was used for data analysis, with three categories listed, usability, technical aspects and pedagogical practice. The results demonstrate that when using the tool as a stimulus in the production of study units, the teachers shared their own work, promoting the exchange of contents and extolling the characteristics of the tool, in relation to the other conventional means previously used in the production of content. . Therefore, it is concluded that the use of an application contributes to best practices and strategies for sharing content among teachers.
\end{abstract}

Keywords: Applications. Mobile learning. Pedagogical strategies. Educational network technologies. 


\section{Introdução}

A contemporaneidade nos mostra que evoluir sempre será uma necessidade, devido a inúmeras características e fatores da existência humana. Percebemos, hoje, que uma tecnologia evoluiu quando ela se torna imperceptível ou transparente, baseados na premissa de que não nos lembramos de quantas vezes a utilizamos em um único dia - como a energia elétrica. Essa analogia se traduz atualmente para o modo de compartilhar informações ou práticas online nos mais diferentes ambientes virtuais.

Hoje, a mobilidade e flexibilidade dos conteúdos são primordiais para a democratização e inserção da informação e, isso em diferentes plataformas. Diversos autores, como Nichele; Schlemmer (2014) enfatizam que a aprendizagem móvel é uma prática com potencial inovador, podendo mudar o processo de aprendizagem, ampliando as possibilidades de estratégias de ensino e promovendo a colaboração e a cooperação entre alunos e professores. Já Oliveira (2013) destaca que o uso de tecnologias de informação e comunicação (TIC) promove o desenvolvimento da educação, pois a introdução de conceitos relacionados a novos recursos pode facilitar a interpretação do conteúdo, melhorando assim o aprendizado.

Nesse sentido, Twenge (2017) menciona que os jovens e adolescentes que agora estão na escola são considerados pertencentes à geração conectada porque sempre utilizam dispositivos de comunicação, entretenimento e produção de conteúdo de acordo com seus objetivos. Hoje, softwares, como os aplicativos para celulares, sincronizam os trabalhos em diferentes plataformas, permitindo a continuidade do desenvolvimento da experiência da aprendizagem, em qualquer espaço. Além disso, a independência de equipamentos caros, como processadores e memórias, e a necessidade de ter apenas uma conexão com internet, é outro importante fator que potencializa a computação nas nuvens, aliada a este tipo de aprendizagem.

Uma das soluções propostas seria então melhorar a qualidade da educação e assegurar oportunidades sustentáveis de aprendizagem para todos através das TIC. Sem desmerecer a importância e sua utilidade, a tecnologia por si só não pode determinar a capacidade da aprendizagem no que se refere ao benefício da aprendizagem. Essa forma de aprender pode se tornar uma alternativa viável para promover situações de inovação nas práticas pedagógicas em todas as áreas do conhecimento, de maneira a possibilitar a experimentação, a utilização e a exploração das tecnologias (Behar et al., 2019). Assim a aprendizagem móvel ligada a uma metodologia contínua e sustentável nas escolas, propicia e fomenta o objetivo de integração de ferramentas na busca do conhecimento, fornecendo um espaço único e amplo na disposição de recursos para aprendizagem de cada aluno. Isto significa, um espaço que se mostra importante como forma de elencar novas metodologias, discutir novas propostas de ensino e, principalmente, promover o acesso de todos ao conteúdo, estando ou não em sala de aula.

Atualmente, o desenvolvimento de conteúdo digital é uma tendência global, principalmente quando nos referimos a dispositivos móveis, focado quase que exclusivamente em livros didáticos acessados por leitores eletrônicos (Sharples, 2012). Além desse tipo de conteúdo, a criação de aplicativos móveis e plataformas de software procura demonstrar o grande leque existente em recursos digitais usando os dispositivos móveis.

A distribuição de conteúdo fortaleceu o lado comercial dos aplicativos móveis, gerando um grande estímulo no desenvolvimento de programas para esses dispositivos. Ferramentas para resolução de atividades pedagógicas, cálculos, anotações, digitação e criação de conteúdo são opções proporcionadas pelos aplicativos. Um estudo do Sistema Global para Comunicações Móveis (GSMA, 2012) constatou que já no ano de 2011, foram baixados mais de 270 milhões de aplicativos pedagógicos.

Os dispositivos móveis proporcionam uma renovação sobre as possibilidades educacionais, como pesquisas, estudos e discussões. Esse ambiente permite o acesso a uma gama enorme de ferramentas gratuitas ou pagas, em que, através de uma consulta prévia na store, filtra-se o conteúdo desejado, como para o uso em sala de aula. Esse espaço de 
convergência da Internet com as telecomunicações viabiliza a aprendizagem móvel, criando uma ampla rede de comunicação, aliada a oportunidades de fomento para aprendizagem como um todo. Essa perspectiva faz com que a sala de aula seja reposicionada, e todos os espaços fora dela, sejam vistos como lugares possíveis para ensinar e aprender.

Portanto, essa necessidade de novas perspectivas da aprendizagem móvel, que permita a competência em fornecer novas oportunidades na troca de informações com apoio da tecnologia, é imprescindível na diversificação de fontes acadêmicas e principalmente no que tange ao uso profissional docente na elaboração de novas estratégicas pedagógicas.

No entanto, promover uma integração que resulte na facilidade do uso dessas características distintas e para isso, utilizando de métricas específicas de avaliação, tornam a usabilidade imprescindível na execução de qualquer projeto. Com um conjunto de regras e boas práticas no aprendizado e uso, e avaliando também a satisfação dos envolvidos através desse feedback, é possível entender o alcance dos objetivos específicos de determinado aplicativo. Assim, a aprendizagem aliada à utilização eficiente e gestão de erros são itens importantes para que o usuário perceba a fluência da usabilidade de um sistema. Sobre isso Nielsen (2014) aponta que, para ocorrer este processo com efetividade é necessário definir os componentes qualitativos.

Através destes parâmetros é possível definir que a usabilidade está ligada diretamente a realização das solicitações de forma correta e com menos erros, caracterizando assim a sua eficácia. Ainda é possível determinar o nível de esforço na realização dessas tarefas, já que com menos erros e alcançando os mesmos objetivos, tem-se a eficiência mensurada.

Relacionando essas questões à atuação docente, é imperativo que os profissionais docentes utilizem novas estratégias para renovar sua prática em sala de aula, pois como já dizia Demo (1998, p. 206) “o mundo mudou muito e hoje em dia determinadas práticas já não servem como comprovação de competência, já que a prática que interessa é aquela que se renova sempre". Para Souza (2006) a prática pedagógica é a ação maior do trabalho educacional e contempla três dimensões, docente, gestora e discente. Este estudo reserva-se a tratar a dimensão docente, aquela exercida pelo professor em sala de aula com seus discentes.

Assim, sabe-se que os professores dispõem atualmente de livros, sites, repositórios, artigos, revistas entre outros tipos de mídia, para elaborar os conteúdos propostos pela área pedagógica, para desenvolverem em uma turma ou em ano escolar específico e que esse conteúdo pode ser replicado a outros professores, em outras turmas e outros anos. Muitas vezes ocorre que os conteúdos não estão reunidos de forma a facilitar o trabalho pedagógico a partir do compartilhamento de experiências e boas práticas de ensino, com a utilização de determinado conteúdo. Dessas afirmativas, decorre o objetivo da pesquisa que é analisar como um aplicativo de compartilhamento de conteúdo pode contribuir com a prática docente.

\section{Metodologia}

O presente trabalho tem como enfoque uma pesquisa do tipo aplicada, que procura fomentar o conhecimento e tem como foco "a resolução de problemas ou necessidades concretas e imediatas" (Appolinario, 2014, p. 152). A abordagem utilizada no desenvolvimento deste trabalho e ao enfoque do problema, foi do tipo qualitativa, que prioriza compreender e interpretar comportamentos, expectativas, opiniões extraídas do levantamento dos dados.

O locus para qual o trabalho foi idealizado é uma Escola Estadual, em um município do interior do RS, que possui 2 cursos Técnicos Subsequentes ao Ensino Médio: Administração e Informática. Para a base do estudo foram escolhidos cerca de 20 professores para utilizarem e avaliarem a ferramenta.

Como instrumento de coleta de dados foi utilizado o questionário, que Marconi e Lakatos (2003, p. 201) definem como sendo "um instrumento de coleta de dados, constituído por uma série ordenada de perguntas, que devem ser respondidas por escrito e sem a presença 
do entrevistador". O questionário se utilizou de perguntas do tipo abertas e fechadas, sendo que para responder as perguntas fechadas, os participantes tinham cinco opções, conforme a escala Likert.

A análise dos dados utilizou-se da análise categorial, proposta por Bardin (2011), para a qual foram constituídas três categorias: Usabilidade, Práticas Pedagógicas e Aspectos Técnicos, conforme expresso no Quadro 1.

Quadro 1 - Categorias

\begin{tabular}{|l|l|l|}
\hline Categorias & Definição no Estudo & Objetivos \\
\hline Usabilidade & $\begin{array}{l}\text { A capacidade que um } \\
\text { sistema interativo pode } \\
\text { oferecer em realizar de } \\
\text { forma eficaz, rápida e com } \\
\text { sucesso a execução de } \\
\text { suas tarefas }\end{array}$ & $\begin{array}{l}\text { Investigar e qualificar a forma como o } \\
\text { aplicativo pode ser utilizado, } \\
\text { coletando informações para análise de } \\
\text { deficiências e vantagens quanto ao } \\
\text { uso. Entender como a fácil } \\
\text { aprendizagem, utilização eficiente e } \\
\text { gestão de erros norteia a boa } \\
\text { usabilidade. }\end{array}$ \\
\hline $\begin{array}{l}\text { Aspectos } \\
\text { Técnicos }\end{array}$ & $\begin{array}{l}\text { Características de } \\
\text { utilidade, em que se } \\
\text { permite analisar } \\
\text { capacidade do sistema a } \\
\text { realizar funcionalmente o } \\
\text { que é necessário. }\end{array}$ & $\begin{array}{l}\text { Determinar se ocorreram problemas } \\
\text { técnicos e a efetividade de suas } \\
\text { funcionalidades como propósito de } \\
\text { repositório móvel. }\end{array}$ \\
\hline $\begin{array}{l}\text { Práticas } \\
\text { Pedagógicas }\end{array}$ & $\begin{array}{l}\text { Desenvolvimento } \\
\text { Unidades de Ensino }\end{array}$ & $\begin{array}{l}\text { Apontar de que forma o } \\
\text { compartilhamento de metodologias } \\
\text { ajuda na preparação de ementas, na } \\
\text { elaboração de aulas e no fomento do } \\
\text { conhecimento entre os professores. }\end{array}$ \\
\hline
\end{tabular}

Fonte: Autores (2020).

A pesquisa foi dividida em fases para seu desenvolvimento, a saber:

1- Pesquisa de Mercado - Etapa para verificar e analisar a disponibilidade de ferramentas que contemplam de alguma forma o problema apresentado.

2- Pesquisa bibliográfica - Elaboração do Referencial Teórico para o desenvolvimento do trabalho.

3- Escolha do aplicativo - O aplicativo escolhido chama-se Sistema Escolar, o qual foi desenvolvido pelo pesquisador, através da ferramenta AppBuilder, por ser gratuita e utilizar o conceito de blocos de montagem para a criação do app. O aplicativo permite que cada professor cadastre conteúdos por disciplinas ou unidades de ensino e compartilhe esses conteúdos com outros professores.

4- Utilização do aplicativo - etapa em que os usuários utilizaram e testaram as ferramentas disponíveis.

5- Aplicação do questionário.

6- Análise dos questionários e escrita dos resultados encontrados.

\section{Resultados}


O aplicativo foi disponibilizado aos professores da Escola durante quinze dias, por meio de um grupo de rede social dos professores (WhatsApp), com instruções e orientações sobre a finalidade da ferramenta. Foram enviados além do App, o formulário com as questões referentes à análise e levantamento da satisfação dos usuários com o produto. As respostas dos questionários da pesquisa qualitativa foram tabuladas através da análise de categorias propostas na fase de desenvolvimento por Bardin (2011), onde o respondente foi convidado a emitir o seu nível de concordância com uma frase, sobre uma determinada categoria.

Foram obtidas 11 respostas junto aos professores envolvidos e assim, através da métrica de pontos atribuída, identificados os seguintes resultados. No Bloco 1, identificação e experiência profissional, todos os professores possuem pós-graduação envolvendo as áreas de Administração, Informática, Pedagogia, Língua Portuguesa, Educação Física e Letras. Todos citaram ferramentas como Youtube, Google, Classroom, Edmodo entre outras, no uso cotidiano de trabalho. Quando questionados sobre a abordagem pessoal da tecnologia como forma de apoio para ministrar as aulas, enfatizaram a importância das TIC junto ao ensino e destacaram a onipresença dos celulares junto aos alunos.

Portanto, pode-se concluir que os professores têm um bom conhecimento das tecnologias e que nesse sentido, acredita-se que esses espaços podem proporcionar possibilidades para construir e melhorar o conhecimento em qualquer tempo e espaço (Silveira Sonego et al., 2019), além de fomentar a criação de estratégias pedagógicas por meio de suas funcionalidades (Carvalho et al., 2011).

No bloco 2, que trata especificadamente sobre o aplicativo e sua usabilidade, ou seja, a primeira categoria elencada, foram feitas as seguintes pontuações nas respostas. Quando questionados sobre a colaboração do app na produção das aulas, obteve-se os percentuais de que $63,6 \%$ concordam parcialmente que é satisfatória e 36,4\% apontaram que concordam totalmente.

Focando na usabilidade da ferramenta cerca de $63,6 \%$ concordam parcialmente na efetividade da proposta do aplicativo, outros $9,1 \%$ ficaram neutros e $27,3 \%$ admitiram que o aplicativo melhorou a motivação da produção textual das atividades escolares. Esses percentuais destacam que para grande maioria dos professores, na categoria de usabilidade, a ferramenta atende plenamente, enfatizando que para um resultado positivo. Como precursor e estudioso renomado na área de usabilidade Jakob Nielsen (1993) descreve em seu livro Usability Engineering, o sistema deve ser fácil de aprender para que os usuários possam rapidamente começar a interagir com o sistema e desenvolver suas atividades;

Já na busca por conteúdo dentro da ferramenta 90,9\% dos respondentes concordam parcialmente que ajudou na elaboração das estratégias pedagógicas e outros $9,1 \%$ concordam totalmente com essa afirmação.

Desse modo, a primeira categoria sobre Usabilidade foi atendida e referendada, pois segundo Nielsen (2007), os responsáveis por uma ferramenta devem sempre ter em mente a pergunta: Os usuários estão tentando realizar algo quando a utilizam? Como os usuários utilizaram e desenvolveram estratégias nela, a preocupação com a usabilidade foi peculiar na pesquisa

A segunda categoria, aspectos técnicos, a maioria dos envolvidos (90,9\%) afirmou que a ferramenta colabora e inspira para a produção dessas estratégias. Já cerca de $54,5 \%$ dos professores avaliaram o aplicativo positivamente no quesito possuir uma navegação simples e fácil, outros $36,4 \%$ concordam parcialmente e $9,1 \%$ não tem opinião formada sobre a questão. Ainda que $36,4 \%$ dos respondentes informaram que não houve problemas no uso da ferramenta, $27,3 \%$ tiverem algum empecilho, 18,2\% ficaram neutros e 18,2\% afirmaram não encontrar nenhum problema durante o uso. Essas respostas denotam que as ferramentas tecnológicas, através desses aspectos técnicos, podem facilitar o acesso aos conteúdos, favorecendo a fixação dos temas abordados e levar o conteúdo para além da sala de aula (Laurindo; Souza, 2017). 
Em uma análise geral, quanto aos aspectos técnicos, os professores participantes da pesquisa informaram que $45,5 \%$ deles afirma não ter desvantagem técnicas que impeçam seu uso. Já outros $36,4 \%$ concordam parcialmente e $18,2 \%$ disseram que encontraram dificuldades no uso da ferramenta.

Sendo assim, a segunda categoria voltada aos Aspectos Tecnológicos identificou que a aprendizagem móvel é sim uma prática com potencial inovador que pode expandir as possibilidades de estratégias de ensino em diferentes ambientes para promover a colaboração e cooperação entre professores (Nichele; Schlemmer, 2014).

Quanto à terceira categoria, práticas pedagógicas, para analisar o aplicativo como um repositório dessas práticas, foram aplicadas questões que refletissem esse aspecto, e os seguintes resultados foram obtidos: cerca de 18,2\% dos professores avaliaram que as competências presentes no aplicativo contribuem parcialmente na compreensão dessas pelos alunos, e $81,8 \%$ concordam totalmente nesta questão. Diante deste contexto, verifica-se que os dispositivos móveis podem fomentar o desenvolvimento de uma aprendizagem que cria várias "possibilidades de mediar atividades de estudo dentro e fora da sala de aula através dos dispositivos móveis, com base na definição de ensino híbrido" (Sonego, 2019, p. 52). Essa aprendizagem através de um ambiente móvel visa adaptar as tarefas de aprendizagem (Carvalho et al., 2011).

Quanto a relevância de complementar os conhecimentos dos conteúdos disponíveis dos pesquisados, o app foi avaliado em 54,5\% que concordam totalmente com essa afirmação e 45,5\% concordam de forma parcial. Ainda segundo a análise da pesquisa, 54,5\% se sentem mais seguros para desenvolver novas estratégicas através do App e 45,5\% avaliam que concordam de forma parcial.

As respostas obtidas na categoria práticas pedagógicas enfatizam que há necessidade, com o aumento dos aplicativos educacionais, do desenvolvimento de repositórios para o mapeamento, organização, categorização e disponibilização destes aplicativos nos próprios dispositivos móveis. Além disso, autores como Mello; Boll, (2014) acreditam que o aprendizado social dessas práticas pedagógicas poderá revolucionar principalmente os desejos de permanência inclusive dos próprios alunos nos espaços escolares, de maneira a torná-los mais interessantes para essa geração.

Desta forma podemos fazer uma análise mais abrangente com as respostas dos questionários, comparando com os critérios determinados na metodologia, conforme Quadro 2.

Quadro 2 - Quadro de Comparação de Resultados entre Categorias

\begin{tabular}{|c|c|c|}
\hline CATEGORIAS & OBJETIVO & RESULTADO OBTIDO \\
\hline Usabilidade & $\begin{array}{l}\text { A maneira como os usuários } \\
\text { farão o uso funcional do } \\
\text { sistema, podendo ser } \\
\text { aplicada a qualquer área. } \\
\text { Dessa forma, um sistema } \\
\text { pode ser ótimo, de fácil } \\
\text { entendimento, eficaz e } \\
\text { eficiente para certas pessoas, } \\
\text { enquanto que para outras ele } \\
\text { pode ser inadequado, } \\
\text { complicado de manusear e } \\
\text { ineficiente. }\end{array}$ & $\begin{array}{l}\text { No requisito eficiência, a ferramenta } \\
\text { mostrou através dos questionários que os } \\
\text { usuários conseguiram produzir e utilizar } \\
\text { o aplicativo efetivamente; quanto a } \\
\text { minimização de erros encontrados e a } \\
\text { rápida recuperação do sistema, aliada à } \\
\text { satisfação apontada pelo questionário, } \\
\text { mostrou também que o sistema foi de } \\
\text { uso agradável. Os resultados obtidos } \\
\text { apontam ainda que no desenvolvimento } \\
\text { a preocupação com tamanho de fontes, } \\
\text { disposição de menus, quantidade de } \\
\text { informações, promoveram uma interface } \\
\text { mais clara e intuitiva, pois a maioria dos } \\
\text { pesquisados respondeu que não }\end{array}$ \\
\hline
\end{tabular}




\begin{tabular}{|c|c|c|}
\hline & & $\begin{array}{l}\text { encontrou dificuldades para alcançar } \\
\text { objetivos direcionados com eficiência, } \\
\text { eficácia e satisfação. }\end{array}$ \\
\hline $\begin{array}{l}\text { Aspectos } \\
\text { Técnicos }\end{array}$ & $\begin{array}{l}\text { Características de utilidade } \\
\text { técnica em que se permite } \\
\text { analisar a capacidade do } \\
\text { sistema } \\
\text { funcionalmente o que é } \\
\text { necessário. }\end{array}$ & $\begin{array}{l}\text { Alguns apontamentos de dificuldades } \\
\text { relatados, mostraram que é preciso } \\
\text { analisar tal aspecto. Isso através de um } \\
\text { levantamento, que aponte o tipo de } \\
\text { dificuldade que ocorreu e se essa foi } \\
\text { relevante ou não no uso da ferramenta. O } \\
\text { percentual de dificuldades encontrado } \\
\text { foi baixo, mas uma análise mais } \\
\text { detalhada poderia ser necessária para } \\
\text { apontar soluções. }\end{array}$ \\
\hline $\begin{array}{l}\text { Práticas } \\
\text { Pedagógicas }\end{array}$ & $\begin{array}{l}\text { Desenvolvimento de } \\
\text { Unidades de Ensino com o } \\
\text { uso do aplicativo para } \\
\text { compartilhamento dentro da } \\
\text { ferramenta }\end{array}$ & $\begin{array}{l}\text { Como apontado pelas respostas, os } \\
\text { professores conseguiram utilizar a } \\
\text { ferramenta para se inspirarem na } \\
\text { produção desses conteúdos e após } \\
\text { compartilharam no ambiente. Esses } \\
\text { dados apontam que o objetivo foi } \\
\text { alcançado, tanto na promoção de um } \\
\text { repositório móvel quanto na forma de } \\
\text { compartilhar conteúdos desenvolvidos } \\
\text { para uso em sala de aula. }\end{array}$ \\
\hline
\end{tabular}

Fonte: Autores (2020).

Portanto, é um desafio para os professores construir aplicativos educacionais, e é uma necessidade do cotidiano escolar, em que se exige cada vez mais atualizações no uso desses recursos para que possam ajudar os professores. $\mathrm{O}$ uso de uma plataforma gratuita e que não utiliza de linguagem de programação pode facilitar o acesso às possibilidades de desenvolvimento por parte dos professores, de modo a promover a inovação das práticas pedagógicas

\section{Considerações Finais}

Atualmente, a prática docente tem sido beneficiada com a utilização de recursos e ferramentas que auxiliam o desenvolvimento de novas estratégias de ensino, aliada a mobilidade fornecida pelos aplicativos móveis, agregando e fomentando o compartilhamento de conteúdo para a produção das aulas. O presente estudo teve como objetivo analisar como um aplicativo de compartilhamento de conteúdo pode contribuir com a prática docente.

Sendo assim, apresentam-se as considerações relacionadas à análise e interpretação de dados e as conclusões da pesquisa. A análise destacou tópicos, que permitem apontar considerações importantes do estudo.

O aplicativo escolhido permitiu apropriar-se de uma estrutura de desenvolvimento acessível e de fácil compreensão, criando uma ferramenta com propósito claro e definido. Já em se tratando da primeira categoria, focada em usabilidade, o estudo mostrou que ao utilizar a ferramenta, os profissionais docentes conseguiram absorver e compreender as instruções de uma maneira eficiente e objetiva. Na segunda categoria, sobre os aspectos técnicos destaca-se 
que, a adoção de metodologias participativas, a partir de propostas construtivistas, como a criação de Apps, pode-se despertar o interesse dos profissionais docentes na criação e uso desses espaços, promovendo inclusive um maior acesso de professores a ambientes como este, visto que muitos compartilharam suas estratégias de ensino dentro da ferramenta.

A terceira categoria analisou a prática pedagógica, na qual foi observada a sua relevância como fomento do conhecimento, que vai além de incitar os profissionais docentes a criarem e trazerem de uma forma inovadora para o ambiente de sala de aula, novas tarefas e atividades, pois permitiu a troca efetiva e colaborativa de conteúdo, por meio do aplicativo.

A partir dessas considerações, a análise dos dados possibilitou algumas conclusões, como a potencialidade da aprendizagem móvel, que pode oportunizar práticas e dinâmicas que promovam uma maior integração entre os docentes. Para tanto, é importante destacar que os professores devem manter-se em formação, para que essas experiências permitam explorar cada vez mais os dispositivos móveis, fomentando subsídios teórico-práticos para realizarem o planejamento e a implementação de atividades escolares usando essa tecnologia.

Por fim, pode-se concluir que o uso de um aplicativo específico que permita que o professor compartilhe conteúdos, como instruções educacionais e busque por eles para sua área, exalta uma forma rápida e de fácil acesso a todos os profissionais docentes, promovendo a aprendizagem móvel como ferramenta de apoio neste processo de aprendizagem.

\section{Referências}

APPOLINÁRIO, F. Dicionário de metodologia científica: um guia para a produção do conhecimento científico. São Paulo: Atlas, 2004.

BARDIN, L. Análise de conteúdo. São Paulo: Edições 70, 2011.

BEHAR, P. A. Recomendação Pedagógica em Educação a Distância. Porto Alegre: Penso, 2019. $208 \mathrm{p}$.

CARVALHO, A. S.; BASTOS, H. P. P.; LEITE, M. L. F. T. T; DA COSTA, R. G. Educação e Tecnologia: um percurso interinstitucional. Campos dos Goytacazes: Essentia Editora, 2011. 272p.

DEMO, Pedro. Questões para a teleducação. Petrópolis: Vozes, 1998.

GSMA. GSMA announces new global research that highlights significant growth opportunity for the mobile industry. London: GSMA, 2012. Disponível em: $<$ http://www.gsma.com/newsroom/gsma-announces-new-global-research-that-highlightssignificantgrowth-opportunity-for-the-mobile-industry/\#.UzB31VS5fcs>. Acesso em: 08 Janeiro, 2019.

LAURINDO, A. K. S.; SOUZA, P. H. S. Aplicativos educacionais: um estudo de caso no desenvolvimento de um aplicativo na plataforma app inventor 2 para auxílio no ensino de produção textual nas aulas de português. 2017. 69 f. TCC (Graduação) - Curso de Tecnologias da Informação e Comunicação, Universidade Federal de Santa Catarina, Araranguá, 2017.

MARCONI, M. de A.; LAKATOS, E. M. Fundamentos de metodologia científica. 5. ed. São Paulo: Atlas, 2003.

MELO, R. S; BOLL, C. I. Cultura Digital e Educação: desafios contemporâneos para a aprendizagem escolar em tempos de dispositivos móveis. Revista Novas Tecnologias na Educação. $\quad$ v. $12 . \quad$ p. $1-11, \quad 2014 . \quad$ Disponível em: https://seer.ufrgs.br/renote/article/view/49829/31187. Acesso em: 30 out. 2020. 
NICHELE, A. G.; SCHLEMMER, E. Aplicativos para o ensino e aprendizagem de Química. Renote - Revista Novas Tecnologias na Educação, Porto Alegre, v. 12, n. 2, p.1-9, 2014

NIELSEN, Jakob; BUDIU, Raluca. Usabilidade móvel. Rio de Janeiro: Elsevier, 2007.

NIELSEN, Jakob. Usability Engineering. San Diego: Academic Press, 1993.

OLIVEIRA, T. T. Uso de TICs no ensino de Biologia: um olhar docente. 2013. 35 Fls. Monografia (Especialização em Educação: Métodos e Técnicas de Ensino). Universidade Tecnológica Federal do Paraná, Medianeira, 2013

SILVEIRA SONEGO, A. H., \& BEHAR, P. A. M-learning: o uso de dispositivos móveis por uma geração conectada. Revista Educação (Porto Alegre), v. 42, n. 3, 525-534. set.- dez. 2019. https://doi.org/10.15448/1981-2582.2019.3.32203. Disponível em: https://revistaseletronicas.pucrs.br/ojs/index.php/faced/article/view/32203. Acesso em: 30 out 2020.

SHARPLES, M. Technology-Enhanced Learning: principles and products. Netherlands: Springer, 2012.p. 233-249

SONEGO, A. H. S. ARQPED-MOBILE: Uma arquitetura pedagógica com foco na aprendizagem móvel. Porto Alegre: UFRGS, 2019. 241p. Tese de Doutorado. Disponível em: https://lume.ufrgs.br/handle/10183/197443. Acesso em: 30 out 2020.

SOUZA, João Francisco de. Prática pedagógica e formação de professores. Recife: Bagaço, 2006.

TWENGE, J. M. iGen: why today's super-connected kids are growing up less rebellious, more tolerant, less happy and completely unprepared for adulthood. New York: Atria Books, 2017. 